\section{CLIN ICAL PRACTICE}

\title{
Long-Acting Methods of Contraception
}

\author{
Herbert B. Peterson, M.D., and Kathryn M. Curtis, Ph.D.
}

This Journal feature begins with a case vignette highlighting a common clinical problem. Evidence supporting various strategies is then presented, followed by a review of formal guidelines, when they exist. The article ends with the authors' clinical recommendations.

\begin{abstract}
A healthy, multiparous 23-year-old woman requests advice about contraception. Her last child was conceived while she was using oral contraceptives, which she took irregularly. She wants no more children and desires a highly effective and long-acting method of contraception. She is sexually active in a monogamous relationship and had been treated for gonococcal cervicitis at the age of 16 years. She has normal menses. Findings on pelvic examination are normal. What contraceptive methods are appropriate for her?
\end{abstract}

\section{THE CLINICAL PROBLEM}

Modern contraceptives have enabled countless women and couples to plan their pregnancies; nevertheless, approximately 80 million unintended pregnancies occur each year worldwide. In the United States, nearly half (48 percent) of women aged 15 to 44 are estimated to have had at least one unplanned pregnancy. ${ }^{1}$ Although many of these unplanned pregnancies occur among women not using contraception, slightly more than half (53 percent in 1994) occur while women are using contraceptives. ${ }^{1}$ Many of these pregnancies result from incorrect or inconsistent use of contraception, but some are true failures of the contraceptive method. ${ }^{2}$

Contraceptive methods vary in their effectiveness and in the determinants of effective use. For example, oral contraceptives are highly effective when taken properly but are less effective as used typically. ${ }^{2}$ Injectable methods of contraception offer an alternative to daily pill taking but require reinjection at regular intervals. Other highly effective methods that do not require frequent effort are available, and these long-acting methods are the focus of this review. Two of these methods - intrauterine devices (IUDs) and progestin implants - can be used by women regardless of whether they are spacing their pregnancies or have completed childbearing. Two other methods tubal sterilization for women and vasectomy for men - are intended only for those who are certain that they wish to prevent pregnancy permanently.

\section{STRATEGIES AND EVIDENCE}

IUDs

Worldwide, IUDs are the most popular nonpermanent method of contraception, used by nearly 160 million women. However, only 2 percent of women using contraception in the United States in 2002 used these devices. ${ }^{3}$ Two IUDs are currently available in the United States: the copper T380A (ParaGard, FEI Women's Health), which has a copper surface area of approximately $380 \mathrm{~mm}^{2}$, and the levonorgestrel-releasing intrauterine system (Mirena, Berlex Laboratories), which releases levonorgestrel at a rate of approximately $20 \mu \mathrm{g}$ per day.

IUDs are highly effective in preventing pregnancy (Table 1). A recent analysis found

From the Department of Maternal and Child Health, School of Public Health, and the Department of Obstetrics and Gynecology, School of Medicine, University of North Carolina at Chapel Hill, Chapel Hill (H.B.P.); and the Division of Reproductive Health, Centers for Disease Control and Prevention, Atlanta (K.M.C.).

N Engl J Med 2005;353:2169-75.

Copyright (c) 2005 Massachusetts Medical Society. 


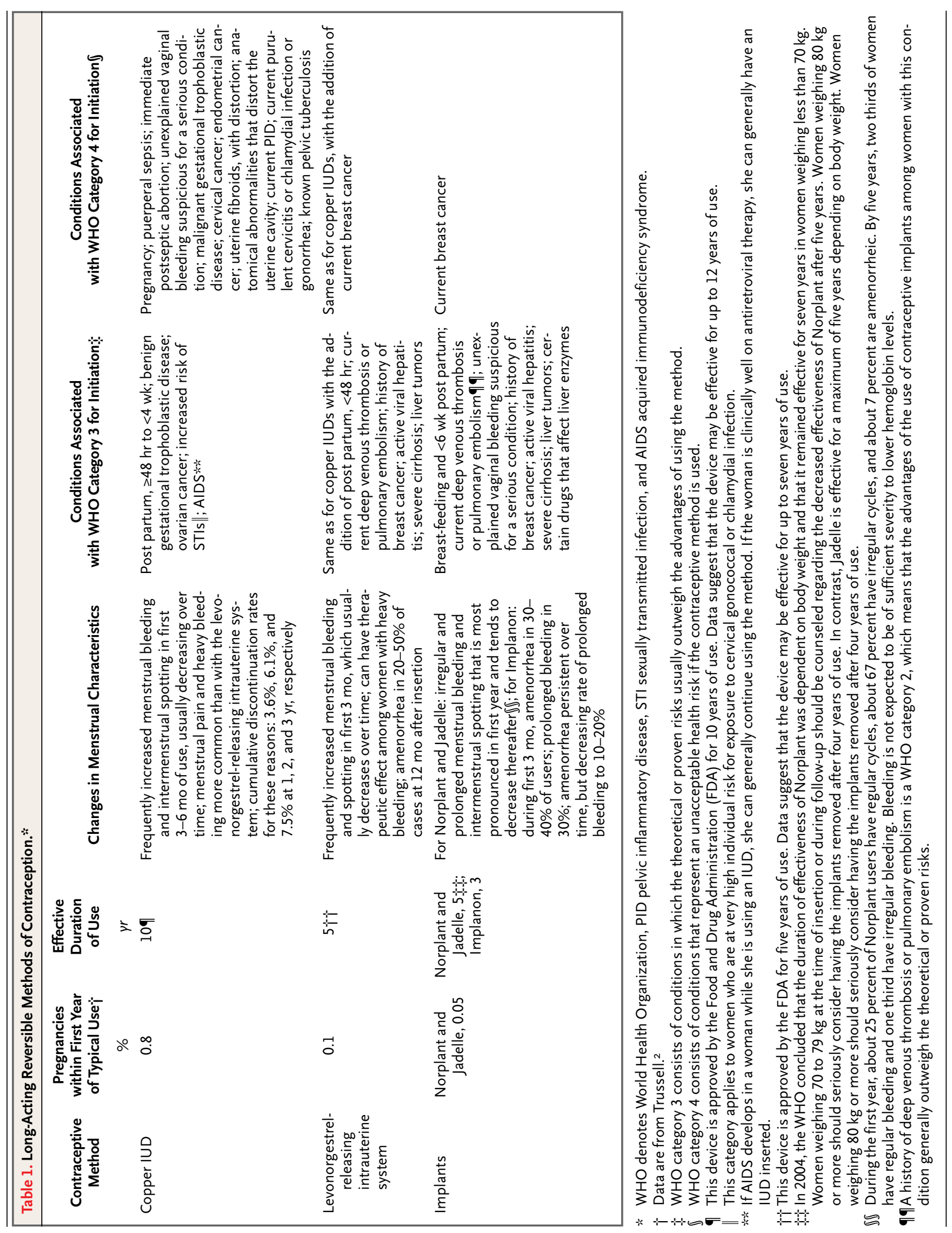


that the copper T380A and the levonorgestrelreleasing intrauterine system were the most costeffective, nonpermanent methods of contraception for five years of use from the perspective of thirdparty payers. ${ }^{4}$ Multiple mechanisms of action probably contribute to the effectiveness of IUDs ${ }^{5-10}$; the precise contribution of each mechanism is unclear, and the extent to which prevention of implantation plays a role is controversial. ${ }^{7-10}$ There is evidence, however, that the copper T380A works primarily by prevention of fertilization through mechanisms that include adverse effects on sperm.5,6

The likelihood of expulsion of an IUD can be reduced with proper insertion technique. Reported rates of expulsion vary widely. ${ }^{11}$ In a large, multicountry trial with seven years of follow-up, cumulative discontinuation rates for expulsion with the copper T380A and the levonorgestrel-releasing intrauterine system were 1.8 and 2.9, respectively, per 100 years of use. ${ }^{12}$ Expulsion is believed to be more common among young and nulliparous women, ${ }^{11}$ although this is uncertain. ${ }^{13}$

In the uncommon event of pregnancy while using an IUD, the risk of complications - including ectopic gestation, spontaneous abortion, and preterm delivery - is increased. ${ }^{11}$ The absolute risk of ectopic pregnancy, however, is low (approximately 1 per 1000 person-years) and is less than half the risk for women using no contraception. ${ }^{14}$ If the pregnancy is intrauterine, the Food and Drug Administration (FDA) recommends that the device be removed, if removal can be accomplished without an invasive procedure. Whether in utero exposure to levonorgestrel increases the risk of fetal abnormalities is unknown.

The main side effects of IUDs are menstrual abnormalities. Heavy bleeding, intermenstrual spotting, and menstrual pain are common among the users of copper IUDs; amenorrhea is more common among users of the levonorgestrel-releasing intrauterine system (Table 1). In a report from Finland, women who were provided information about the possibility of amenorrhea were significantly more likely to be satisfied with the levonorgestrel-releasing intrauterine system than were women who had not received this information. ${ }^{15}$

The popularity of IUDs declined markedly in the United States during the $1980 \mathrm{~s},{ }^{3}$ after reports of serious pelvic infections with use of the Dalkon Shield, which was marketed in the early 1970s. Studies in the late 1980s and 1990s, however, provided strong and reassuring evidence that women at low risk for sexually transmitted infections were at low risk for pelvic infections with the use of IUDs. ${ }^{16-19}$ Combined data from 13 World Health Organization (WHO) studies that excluded women with sexually transmitted infections during the previous six months and those with previous pelvic inflammatory disease and involved more than 50,000 person-years of follow-up, found that the risk of pelvic inflammatory disease was 1.6 cases per 1000 person-years; the risk was concentrated in the first 20 days after insertion. ${ }^{18}$ Randomized trials of women at low risk for sexually transmitted infections have found no benefit of antibiotic prophylaxis in reducing this insertion-associated risk; rates of pelvic infections were comparably low with prophylaxis (0.1 to 1.7 percent) and without prophylaxis ( 0.1 to 2.5 percent). ${ }^{20}$

IUDs appear to cause little, if any, increase in the risk of infertility among women who are at low risk for sexually transmitted infections. ${ }^{17,21}$ At least three case-control studies have found no association between the use of IUDs and infertility among nulligravid women who had previously used a copper IUD. $22-24$

The risk of uterine perforation is low when proper insertion techniques are used. ${ }^{11} \mathrm{~A}$ recent large cohort study in New Zealand found a rate of 1.6 perforations per 1000 insertions performed by nearly 1700 physicians. ${ }^{25}$

\section{PROGESTIN IMPLANTS}

Several subdermal implants provide highly effective, long-acting contraception. These implants consist of polymer capsules or rods that deliver a progestin. Four progestins have been used in implants to date: levonorgestrel, etonogestrel, Nestorone, and nomegestrol acetate. None of these implants are currently marketed in the United States, although two levonorgestrel implants - a set of six silicone elastomer capsules (Norplant) and a set of two silicone elastomer rods (Jadelle) - have been approved by the FDA. Implanon consists of a single rod that contains the progestin etonogestrel; it has been approved for three years of use in the European Union, Canada, and Indonesia and is currently under review by the FDA.

Progestin implants are highly effective (Table 1 ), with recent multinational studies reporting five-year cumulative pregnancy rates of 1.5 percent or less for Norplant and Jadelle. ${ }^{26}$ Although long-term studies are lacking, Implanon appears to be at least as effective as Norplant and Jadelle. ${ }^{26}$ The multiple 
mechanisms of action for progestin-only implants have been reviewed in detail elsewhere. ${ }^{27}$ Although all progestin-only implants have at least some effect on ovarian function, Implanon was specifically designed to prevent ovulation and is highly effective in doing so. ${ }^{27}$ A review of 55 observational studies $^{28}$ found no increase in the rates of adverse outcomes, including pelvic inflammatory disease, loss of bone mineral density, anemia, thrombocytopenia, and death in women who used implants, as compared with nonusers. Although data were insufficient to draw conclusions regarding cardiovascular events (stroke, myocardial infarction, thromboembolism) and cancers, absolute rates for these outcomes were very low (less than 1 per 10,000 person-years).

The main side effect of progestin-only implants, as with other progestin-only contraceptives, is menstrual abnormalities. ${ }^{29}$ Rates and types of menstrual abnormalities vary by implant and the time after insertion (Table 1).

\section{TUBAL STERILIZATION}

Approximately 180 million women worldwide have undergone tubal sterilization. In 2002 in the United States, 28 percent of women between the ages of 30 and 34 years who used contraception had undergone the procedure. ${ }^{3}$ Approximately half of tubal sterilizations in the United States are performed post partum with the use of partial salpingectomy, either by minilaparotomy after vaginal delivery or concurrent with cesarean delivery. Most other procedures are performed by laparoscopy at a time unrelated to delivery with the use of either coagulation or application of clips or bands. In 2002, the FDA approved a new tubal occlusion device (Essure, Conceptus) that is placed with use of hysteroscopy.

Tubal sterilization is highly effective. The cumulative probability of pregnancy at 10 years after the procedure ranges from 1.8 to 54.3 per 1000 procedures and varies with factors including age and method of occlusion ${ }^{30}$ (although data are insufficient to identify any one method as clearly superior). When pregnancies occur after tubal sterilization, a high proportion are ectopic ( 15 to 65 percent, depending on the procedure), ${ }^{31}$ although the absolute risk of ectopic pregnancy is very low after this procedure. An analysis of data from the U.S. Collaborative Review of Sterilization, which included 10,685 women who had undergone sterilization at medical centers in nine U.S. cities, found that the 10-year cumulative probability of ectopic pregnancy for all methods of tubal sterilization examined was 7.3 per 1000 procedures (range, 1.5 to 17.1 per 1000 , depending on the method). ${ }^{31}$ Overall, the proportion of pregnancies that were ectopic was three times as high in years 4 to 10 after sterilization (61 percent) as it was in years 1 to 3 (20 percent).

Deaths associated with tubal sterilization in the United States are rare (approximately 1 to 2 per 100,000 procedures), ${ }^{32}$ and serious morbidity is uncommon. According to the U.S. Collaborative Review of Sterilization, unintended major surgery occurred in 0.9 percent of 9475 laparoscopic sterilizations, and rehospitalization occurred in 0.6 percent; one life-threatening event and no deaths occurred. ${ }^{33}$ Risk factors for complications included diabetes, general anesthesia, previous abdominal or pelvic surgery, and obesity. 33

Although some previous reports described a post-sterilization syndrome involving menstrual abnormalities, more recent data indicate that a syndrome of menstrual abnormalities is no more likely to develop in women undergoing sterilization than in women whose husbands underwent vasectomy. ${ }^{34}$ Although indications for hysterectomy should be the same for women who have undergone sterilization as for women who have not, ${ }^{35}$ women who had undergone sterilization were more likely to undergo subsequent hysterectomy, according to the U.S. Collaborative Review of Sterilization ${ }^{36}$; biologic factors are unlikely to explain this finding. ${ }^{35,36}$ Most women report no change in sexual interest or pleasure after tubal sterilization; of those who report a change, most report an increase. ${ }^{37}$

Sterilization is intended to be permanent and should be performed only in people who are fully informed and choose to prevent pregnancy permanently. Surgical procedures to reverse tubal sterilization and vasectomy - along with the predominant alternative, in vitro fertilization - are expensive and often unsuccessful. The likelihood of pregnancy after surgical reversal of either tubal sterilization or vasectomy depends on several factors, including the method of tubal or vas occlusion and the age of the woman. Although most people remain satisfied with their decision to undergo sterilization, feelings of regret after the procedure are not rare. Women who are sterilized at a young age are at greater risk for later regret, regardless of the number of children they have at the time of sterilization. ${ }^{38}$ According to the U.S. Collaborative Review of Sterilization, the 14-year cumulative probability of requesting information about reversal was 14.3 percent, but the 
probability rose to 40.4 percent among women who were between the ages of 18 and 24 years at the time of sterilization. ${ }^{39}$ The cumulative probability of expressing regret within five years was similar for women who underwent tubal sterilization (7.0 percent) and for women whose husbands underwent vasectomy (6.1 percent). ${ }^{40}$

\section{VASECTOMY}

Worldwide, almost 43 million men have undergone sterilization. In 2002, 9 percent of U.S. women of reproductive age who were using contraception relied on vasectomy. ${ }^{3}$ Vasectomy is generally performed on an outpatient basis under local anesthesia, either by the no-scalpel technique (performed through a small puncture) or by incision, and with the use of a variety of methods of occlusion. Vasectomy is highly effective, $, 2,41,42$ with an estimated pregnancy rate for all methods combined of 0.15 percent with typical use in the first year. ${ }^{2}$ The longterm effectiveness of vasectomy is less well studied than that of tubal sterilization; the long-term effectiveness of vasectomy, like that of tubal sterilization, appears to vary by method ${ }^{43}$ (although data are insufficient to identify any one method as clearly superior). It is recommended that the effectiveness of vasectomy be confirmed by semen analysis at three months or more after the procedure. ${ }^{44}$

Surgical complications from vasectomy are infrequent and usually minor, and include hematoma formation, wound infection, acute epididymitis, and sperm granulomas (with each complication reported in less than 5 percent of procedures). ${ }^{42,45}$ Serious complications and deaths are rare. Chronic testicular pain is a possible late complication. Numerous observational studies have provided reassurance that vasectomy does not increase the risk of prostate cancer, testicular cancer, atherosclerosis, or overall mortality. $42,46,47$

\section{AREAS OF UNCERTAINTY}

It is unclear whether infections of the lower genital tract that occur after insertion of IUDs are more likely to ascend into the upper genital tract than if the devices were not present. Thus, whether IUDs pose an increased risk to women in whom gonococcal or chlamydial cervicitis develops or, like other long-acting contraceptive methods, merely do not confer protection from acquiring these infections is uncertain. ${ }^{17}$

Several case-control studies have found a re- duced risk of endometrial cancer associated with the use of copper and nonmedicated IUDs, ${ }^{48,49}$ but it is unclear whether this association is causal. Suppressive effects of the levonorgestrel intrauterine system on endometrial proliferation ${ }^{48}$ might contribute to a reduction in endometrial cancer risk, but this is uncertain.

It is controversial whether there is a post-vasectomy pain syndrome, variably defined as chronic epididymal, scrotal, or testicular pain after vasectomy. ${ }^{50}$ Surveys of men who have undergone vasectomy have yielded reports of "troublesome" pain in 15 percent, ${ }^{51}$ pain that led to seeking medical care in 5 percent, ${ }^{51}$ and pain that affected quality of life in 2 percent. ${ }^{52}$ These surveys had low response rates, lack comparison groups, and may not be generalizable to the general population. The Health Status of American Men study, a retrospective cohort study in which 10,590 men with vasectomy were matched with neighborhood controls, reported an incidence of epididymitis-orchitis occurring more than 12 months after vasectomy of 24.7 per 10,000 person-years, as compared with 13.6 per 10,000 person-years among men without vasectomy; these rates were significantly different but were not adjusted for potential confounders. ${ }^{33}$ Proposed causes of pain after vasectomy include epididymal congestion, nerve entrapment at the vasectomy site, or sperm granulomas. ${ }^{50}$ Limited data from case series suggest that some men with chronic pain after vasectomy who do not respond to conservative therapy improve after vasectomy reversal ${ }^{50}$ or other surgical management.

\section{GU I D E L I N E S}

The WHO has developed recommendations for the use of IUDs and progestin implants (Table 1) and for sterilization procedures. ${ }^{44,54}$ The American College of Obstetricians and Gynecologists has also provided recommendations regarding IUDs and sterilization ${ }^{35,55}$ (Table 2) and progestin-only methods. 56

CONCLUSIONS

AND RECOMMENDATIONS

Women who desire a highly effective, long-acting method of contraception have several options. Most of these women, like the person in the vignette, are appropriate candidates for an IUD or progestin implants. A history of sexually transmitted infection 


\begin{tabular}{|c|c|}
\hline Contraceptive Method & Recommendations \\
\hline $\begin{array}{l}\text { Copper IUD and levonorgestrel-releasing } \\
\text { intrauterine system }\end{array}$ & $\begin{array}{l}\text { Nulligravid and multiparous women at low risk for sexually transmitted dis- } \\
\text { eases who desire long-term, reversible contraception are good candidates. }\end{array}$ \\
\hline Tubal sterilization and vasectomy & $\begin{array}{l}\text { Patients considering sterilization should be advised that the procedure is in- } \\
\text { tended to be permanent; that it will not provide protection against sexu- } \\
\text { ally transmitted diseases (including human immunodeficiency virus in- } \\
\text { fection); that the morbidity and mortality associated with tubal } \\
\text { sterilization (though low) are higher than for vasectomy; that the effec- } \\
\text { tiveness of the two methods is similar; and that the effectiveness of tubal } \\
\text { sterilization is higher than that of short-term reversible methods and } \\
\text { similar to that of the IUD. }\end{array}$ \\
\hline
\end{tabular}

* Recommendations are from the American College of Obstetricians and Gynecologists. ${ }^{35,55}$

would not contraindicate the use of an IUD in a woman whose risk for current and future infections is low. However, a woman who currently has a cervical gonococcal or chlamydial infection should not have an IUD inserted. The most troubling side effects of IUDs and progestin implants are menstrual abnormalities, and women should be informed about these effects; for some women, these problems are acceptable trade-offs for highly effective, long-acting contraception. For couples choosing permanent contraception, both tubal sterilization and vasectomy have low surgical risks and are highly effective; vasectomy, however, is safer and, in gen- eral, appears to be at least as effective. Only women and men who make a fully informed and well-considered decision to prevent pregnancy permanently are appropriate candidates for sterilization. Whether the woman in this vignette meets these criteria could be determined only after careful counseling. Although women should not be denied tubal sterilization because of young age alone, many such women are well served by using another long-acting method, at least for several years.

The findings and conclusions in this report are those of the authors and do not necessarily represent the views of the Centers for Disease Control and Prevention.

\section{REFERENCES}

1. Henshaw SK. Unintended pregnancy in the United States. Fam Plann Perspect 1998; 30:24-9, 46.

2. Trussell J. Contraceptive failure in the United States. Contraception 2004;70:89 96.

3. Mosher WD, Martinez GM, Chandra A, Abma JC, Willson SJ. Use of contraception and use of family planning services in the United States: 1982-2002. Advance data from vital and health statistics. No 350 Hyattsville, Md.: National Center for Health Statistics, 2004.

4. Chiou CF, Trussell J, Reyes E, et al. Economic analysis of contraceptives for women. Contraception 2003;68:3-10.

5. Rivera R, Yacobson I, Grimes D. The mechanism of action of hormonal contraceptives and intrauterine contraceptive devices. Am J Obstet Gynecol 1999;181:1263 9.

6. Mishell DR Jr. Intrauterine devices: mechanisms of action, safety, and efficacy. Contraception 1998;58:Suppl 3:45S-53S.

7. Spinnato JA II. Mechanism of action of intrauterine contraceptive devices and its relation to informed consent. Am J Obstet Gynecol 1997;176:503-6.

8. Sivin I. Mechanism of action of intrauterine contraceptive devices. Am J Obstet Gynecol 1997;177:718-9.
9. Mastroianni LJr. No evidence to support intrauterine contraceptive device and embryo destruction. Am J Obstet Gynecol 1997;177:980.

10. Stanford JB, Mikolajczyk RT. Mechanisms of action of intrauterine devices: update and estimation of postfertilization effects. Am J Obstet Gynecol 2002;187:1699708.

11. Treiman K, Liskin L, Kols A, Rinehart W. IUDs - an update. In: Population reports. Series B. No. 6. Baltimore: Johns Hopkins School of Public Health, Population Information Program, December 1995. 12. Sivin I, Stern J. Health during prolonged use of levonorgestrel $20 \mu \mathrm{g} / \mathrm{d}$ and the copper TCu 380Ag intrauterine contraceptive devices: a multicenter study. Fertil Steril 1994;61: 70-7.

13. Dennis J, Hampton N. IUDs: which device? J Fam Plann Reprod Health Care 2002; 28:61-8.

14. Franks AL, Beral V, Cates W Jr, Hogue CJR. Contraception and ectopic pregnancy risk. Am J Obstet Gynecol 1990;163:1120-3. 15. Backman T, Huhtala S, Luoto R, Tuominen J, Rauramo I, Koskenvuo M. Advance information improves user satisfaction with the levonorgestrel intrauterine system. Obstet Gynecol 2002;99:608-13. 16. Lee NC, Rubin GL, Borucki R. The intra- uterine device and pelvic inflammatory disease revisited: new results from the Women's Health Study. Obstet Gynecol 1988;72: 1-6.

17. Grimes DA. Intrauterine device and upper-genital-tract infection. Lancet 2000; 356:1013-9.

18. Farley TMM, Rosenberg MJ, Rowe PJ, Chen JH, Meirik O. Intrauterine devices and pelvic inflammatory disease: an international perspective. Lancet 1992;339:785-8.

19. Current trends, IUD safety: report of a nationwide physician survey, 1974. MMWR Morb Mortal Wkly Rep 1997;46:969-74.

20. Grimes DA, Schulz KF. Prophylactic antibiotics for intrauterine device insertion: a metaanalysis of the randomized controlled trials. Contraception 1999;60:57-63. 21. Grimes DA. Intrauterine devices and infertility: sifting through the evidence. Lancet 2001;358:6-7.

22. Hubacher D, Lara-Ricalde R, Taylor DJ, Guerra-Infante F, Guzmán-Rodríguez R. Use of copper intrauterine devices and the risk of tubal infertility among nulligravid women. N Engl J Med 2001;345:561-7.

23. Daling JR, Weiss NS, Metch BJ, et al. Primary tubal infertility in relation to the use of an intrauterine device. N Engl J Med 1985; 312:937-41.

24. Cramer DW, Schiff I, Schoenbaum SC, 
et al. Tubal infertility and the intrauterine device. N Engl J Med 1985;312:941-7.

25. Harrison-Woolrych M, Ashton J Coulter D. Uterine perforation on intrauterine device insertion: is the incidence higher than previously reported? Contraception 2003;67:53-6.

26. Glasier A. Implantable contraceptives for women: effectiveness, discontinuation rates, return of fertility, and outcome of pregnancies. Contraception 2002;65:29-37. 27. Croxatto HB. Mechanisms that explain the contraceptive action of progestin implants for women. Contraception 2002;65 21-7.

28. Curtis KM. Safety of implantable contraceptives for women: data from observational studies. Contraception 2002;65:85 96.

29. Hickey M, d'Arcangues C. Vagina bleeding disturbances and implantable contraceptives. Contraception 2002;65:75-84

30. Peterson HB, Xia Z, Hughes JM, Wilcox LS, Tylor LR, Trussell J. The risk of pregnancy after tubal sterilization: findings from the U.S. Collaborative Review of Sterilization. Am J Obstet Gynecol 1996;174:1161-8.

31. Idem. The risk of ectopic pregnancy after tubal sterilization. N Engl J Med 1997;336: 762-7.

32. Escobedo LG, Peterson HB, Grubb GS, Franks AL. Case-fatality rates for tubal sterilization in U.S. hospitals, 1979 to 1980 . Am J Obstet Gynecol 1989;160:147-50.

33. Jamieson DJ, Hillis SD, Duerr A, Marchbanks PA, Costello C, Peterson HB. Complications of interval laparoscopic tubal sterilization: findings from the United States Collaborative Review of Sterilization. Obste Gynecol 2000;96:997-1002.

34. Peterson HB, Jeng G, Folger SG, Hillis SA, Marchbanks PA, Wilcox LS. The risk of menstrual abnormalities after tubal sterilization. N Engl J Med 2000;343:1681-7.

35. ACOG practice bulletin: clinical management guidelines for obstetrician-gynecologists: benefits and risks of sterilization.
Number 46, September 2003: (replaces technical bulletin number 222, April 1996. Obstet Gynecol 2003;102:647-58.

36. Hillis SD, Marchbanks PA, Tylor LR, Peterson HB. Higher hysterectomy risk for sterilized than nonsterilized women: findings from the U.S. Collaborative Review of Sterilization. Obstet Gynecol 1998;91:241 6.

37. Costello C, Hillis SD, Marchbanks PA, Jamieson DJ, Peterson HB. The effect of interval tubal sterilization on sexual interest and pleasure. Obstet Gynecol 2002;100 511-7.

38. Hillis SD, Marchbanks PA, Tylor LR, Peterson HB. Poststerilization regret: findings from the United States Collaborative Review of Sterilization. Obstet Gynecol 1999;93:889-95.

39. Schmidt JE, Hillis SD, Marchbanks PA, Jeng G, Peterson HB. Requesting information about and obtaining reversal after tuba sterilization: findings from the U.S. Collaborative Review of Sterilization. Fertil Steril 2000;74:892-8.

40. Jamieson DJ, Kaufman SC, Costello C Hillis SD, Marchbanks PA, Peterson HB. A comparison of women's regret after vasectomy versus tubal sterilization. Obstet Gynecol 2002;99:1073-9.

41. Jamieson DJ, Costello C, Trussell J, Hillis SD, Marchbanks PA, Peterson HB. The risk of pregnancy after vasectomy. Obstet Gynecol 2004:103:848-50. [Erratum, Obstet Gynecol 2004;104:200.]

42. Schwingl PJ, Guess HA. Safety and effectiveness of vasectomy. Fertil Steril 2000 73:923-36.

43. Labrecque $M$, Nazerali $H$, Mondor $M$ Fortin V, Nasution M. Effectiveness and complications associated with 2 vasectomy occlusion techniques. J Urol 2002;168 2495-8

44. Selected practice recommendations for contraceptive use. 2nd ed. Geneva: World Health Organization, 2005.

45. Alderman PM. Complications in a serie of 1224 vasectomies. J Fam Pract 1991;33 579-84

46. Cox B, Sneyd MJ, Paul C, Delahunt B, Skegg DCG. Vasectomy and risk of prostate cancer. JAMA 2002;287:3110-5.

47. Bernal-Delgado E, Latour-Pérez J, Pradas-Arnal F, Gómez-López LI. The association between vasectomy and prostate cancer: a systematic review of the literature. Fertil Steril 1998;70:191-200.

48. Hubacher D, Grimes DA. Noncontraceptive health benefits of intrauterine devices: a systematic review. Obstet Gynecol Surv 2002;57:120-8.

49. Benshushan A, Paltiel O, Rojansky N, Brzezinski A, Laufer N. IUD use and the risk of endometrial cancer. Eur J Obstet Gynecol Reprod Biol 2002;105:166-9.

50. Nangia AK, Myles JL, Thomas AJ Jr. Vasectomy reversal for the post-vasectomy pain syndrome: a clinical and histological evaluation. J Urol 2000;164:1939-42.

51. McMahon AJ, Buckley J, Taylor A, Lloyd SN, Deane RF, Kirk D. Chronic testicular pain following vasectomy. Br J Urol 1992, 69:188-91.

52. Choe JM, Kirkemo AK. Questionnairebased outcomes study of nononcological post-vasectomy complications. J Urol 1996; 155:1284-6.

53. Massey FJ Jr, Bernstein GS, O'Fallon WM, et al. Vasectomy and health: results from a large cohort study. JAMA 1984;252: 1023-9.

54. Medical eligibility criteria for contraceptive use. 3rd ed. Geneva: World Health Organization, 2004

55. ACOG practice bulletin: clinical management guidelines for obstetrician-gynecologists. Number 59, January 2005: intrauterine device. Obstet Gynecol 2005;105: 223-32.

56. ACOG practice bulletin: the use of hormonal contraception in women with coexisting medical conditions. Number 18, July 2000. Int J Gynaecol Obstet 2001;75:93-106.

Copyright (c) 2005 Massachusetts Medical Society.

\section{CLINICAL TRIAL REGISTRATION}

The Journal encourages investigators to register their clinical trials in a public trials registry. The members of the International Committee of Medical Journal Editors plan to consider clinical trials for publication only if they have been registered (see N Engl J Med 2004;351:1250-1). The National Library of Medicine's www.clinicaltrials.gov is a free registry, open to all investigators, that meets the committee's requirements. 